\title{
Land-use legacies and forest change
}

\author{
Matteo Garbarino (D) Peter J. Weisberg 1
}

Received: 11 October 2020/Accepted: 15 October 2020/Published online: 31 October 2020

(C) Springer Nature B.V. 2020

The importance of land-use legacies for shaping contemporary landscape patterns and processes and for informing landscape management has been widely recognized for at least two decades (Bürgi et al. 2017; Foster et al. 2003), although research on the topic has accelerated dramatically in recent years. From a literature survey based on the WOS database and the search sentence ALL = ("land-use legac*" OR "land use legac*" AND forest*) we found 279 published papers for the period 1985-2020. Statistically speaking these papers reached an $\mathrm{H}$-index of 40 and a total amount of citations of 6591. An increasing trend of published papers on this topic is not surprising (from 1 in 1994 to 30 per year between 2018 and 2020), yet the level of increasing interest from the scientific community has been remarkable, as demonstrated by the astonishing increase of citations per year (Fig. 1). Almost $16 \%$ of the selected papers were published by the journals Forest Ecology and Management, Landscape Ecology and Ecological

M. Garbarino $(\bowtie)$

Department of Agricultural, Forest and Food Sciences, University of Torino, Largo Braccini 2, IT,

10095 Grugliasco, TO, Italy

e-mail: matteo.garbarino@unito.it

\section{P. J. Weisberg}

Department of Natural Resources and Environmental Science, University of Nevada, Reno, Reno,

NV 89557, USA
Applications, but the variability of the disciplines involved highlights the strongly transdisciplinary character of this topic.

This Special Section is focused on how forest landscape history, arising from past land-use, constrains and shapes the future forest response to disturbance, management, and global change. The Special Section includes a subset of a diverse mix of 24 papers from around the world presented at the recent World IALE 2019 conference, encompassing both modeling and empirical approaches to understanding how landscape change in future is strongly dependent upon historical land-use legacies. Although the Special Section is mainly focused on forests, it also includes papers that explore the implications of landuse legacy for non-forested systems, as well as for landscape mosaics that incorporate multiple vegetation types. Finally, it includes works that consider land-use legacies over a range of time spans, including from prehistoric times using paleoecological approaches, as well as from historical times.

Ecologists commonly focus their attention on natural ecosystems, in which the ecological pattern and process under study is not disturbed by the "fuzziness" introduced by human activities. However, in several parts of the world the effects of repeated human action have resulted in cultural landscapes that are predominantly defined by the anthropogenic 


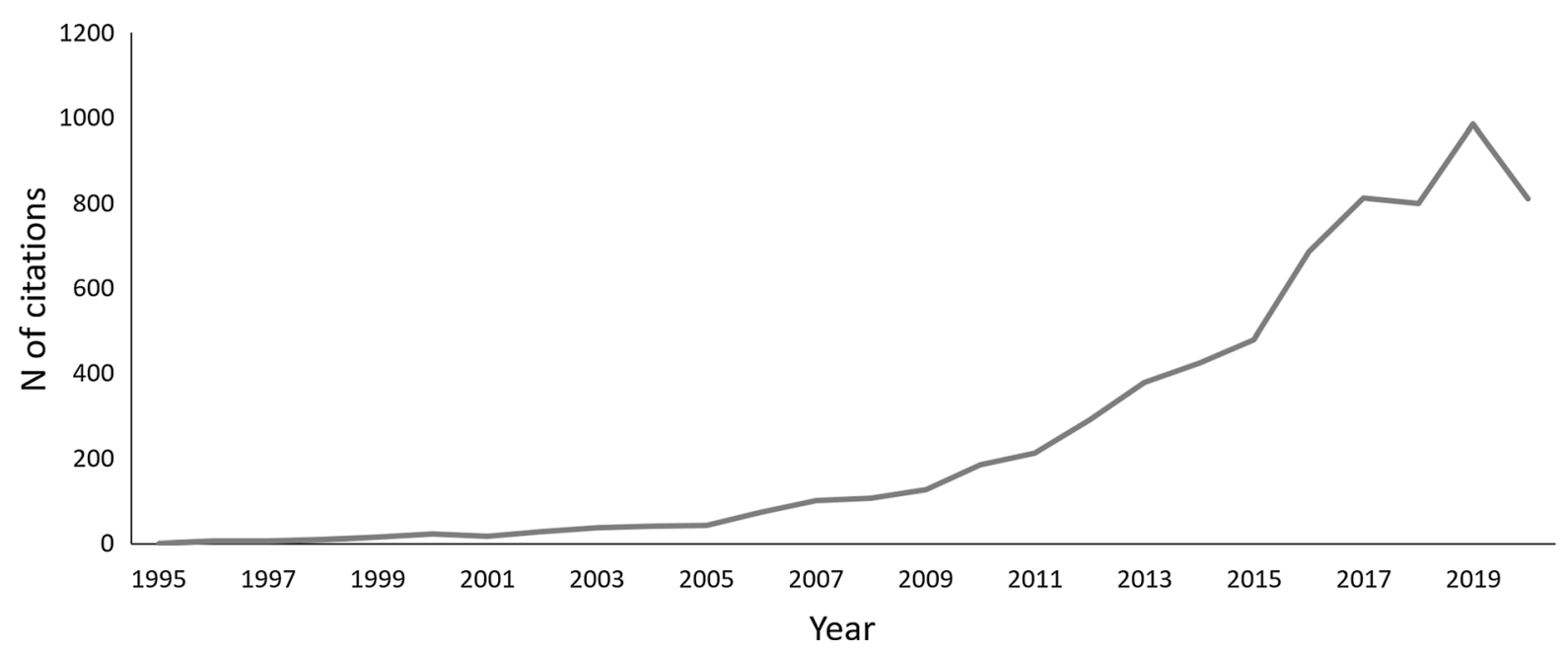

Fig. 1 Number of citations per year for the 1995-2020 period extracted from the WOS database by using the query 'ALL=("land-use legac*" OR "land use legac*" AND forest*)"

disturbance regime (Vos and Meekes 1999; Farina 2000). Historical land uses shape current landscape structure and constrain future ecological processes, resulting in human-modified forest ecosystems that are complex and challenging to study. Historical human influences are difficult to measure and historical data are often scarce, fragmentary or unreliable (Garbarino et al. 2014).

It is now well accepted within the discipline of landscape ecology that land-use legacy effects are pervasive and need to be incorporated into the investigation of contemporary landscape patterns and processes. Our Special Section includes empirical and modeling research projects in which a variety of approaches for assessing historical human impact have been applied to different forest landscapes around the world. Novel metrics and the implementation of longterm monitoring programs could help researchers to disentangle the interacting effects of climate, natural disturbances and land-use on forested cultural landscapes.

Cultural landscapes are complex mosaics characterized by a greater diversity of forest structural types than may otherwise be found in less human disturbed systems (Garbarino et al. 2011). The management of cultural landscapes is a particularly challenging issue in many parts of the world where heavy historical human impact has been followed by a general abandonment. The various papers comprising our Special Section include studies that are diverse in temporal scale (Fig. 2), methodological approach, and geographical region. Several of the manuscripts explicitly integrate ecological research with cultural/ anthropological research, indicative of the broad transdisciplinary nature of land-use legacy studies. In our Special Section we identify four main categories of studies based on the adopted tools and historical data integration, as outlined below.

1 Integration of paleoecological data with other historical sources to assess the importance of land-use legacy on present landscape structure and future dynamics Biological archival data such as dendroecological or paleoecological reconstructions are widely used to reconstruct historical forest dynamics and disturbance regimes. The integration of such data sources with archeological and archival data provide rich and detailed information for understanding land-use legacy effects. We present two papers of this type in this Special Section. Mensing et al. (2020) integrated detailed historical narratives with high-resolution paleoecologic reconstructions, providing a more nuanced examination of the interrelationship between social-economic factors and climate forcing in shaping land-use legacies in the Rieti Basin, central Italy. Klimaszewski-Patterson and Mensing (2020) integrated paleoecological reconstructions and paleolandscape modeling (Landis- 


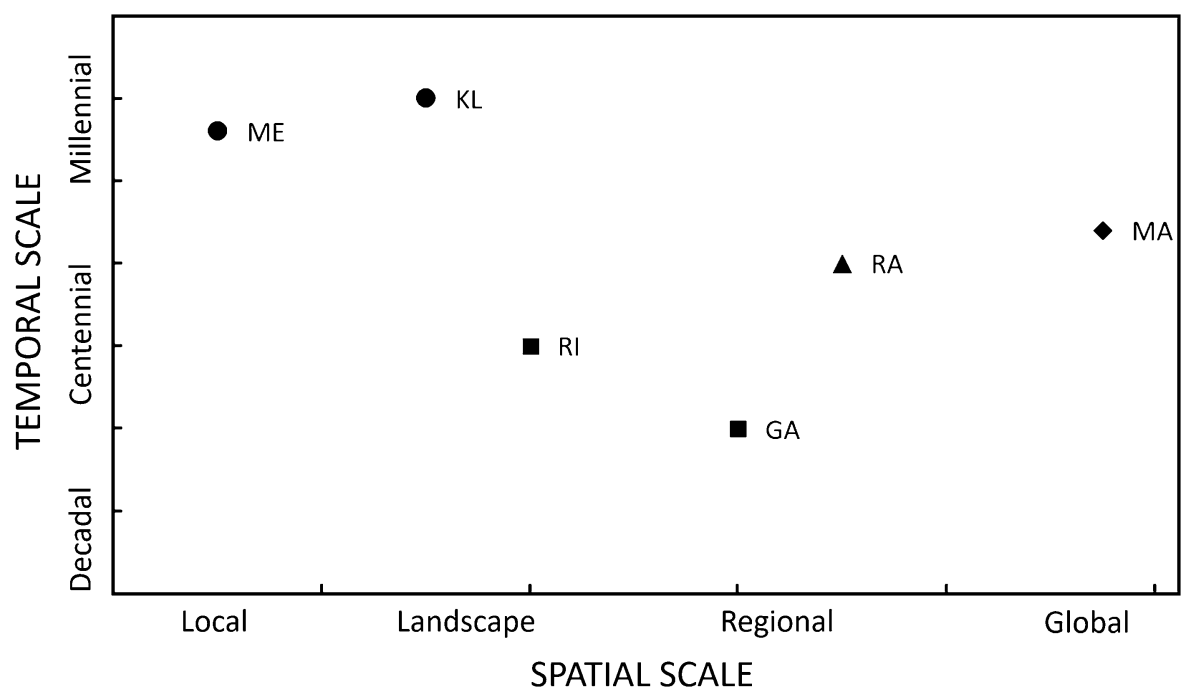

Fig. 2 Spatial and temporal scales covered by the studies presented in this Special Section (ME Mensing et al., $K L$ Klimazewski et al., $R I$ Ridding et al., GA Garbarino et al., $R A$ Raum, MA Mantero et al.). Different symbols indicate main data

II) to examine the relative weights of evidence for whether climate or Native Americans were the driving force of pre-historic forest composition change of Sequoia National Forest, California, USA.

2 Land-use/cover maps as quantitative tools for measuring the effects of land-use legacy on forest landscape dynamics Historical remote sensing data such as aerial photography are classical data sources in land-use change science. Despite technical limits (e.g. spatial and temporal resolutions) due to the heterogeneity of the adopted sensors, land-use maps derived from image classifications for different time periods are fantastic tools to measure changes of landscape configuration and composition. We include two papers of this type. Garbarino et al. (2020) compared recent (60 years) land-use changes in two mountain ranges of Italy expressing different anthropogenic disturbance regimes and forest composition. Their results demonstrate the key role of the historical spatial pattern of forest patches on land-use change. Ridding et al. (2020) adopted a modeling approach (InVEST) to reconstruct historical land cover maps and increase the temporal resolution of the diachronic analysis to multiple time points in the Dorset region, UK. sources adopted in the studies (circle = pollen $/$ charcoal, square $=$ land cover maps, triangle $=$ archival records, diamond $=$ literature review)

\section{Archival data as historical sources to reconstruct} the legacy of past management and policies on current forest landscape structure Historical data on traditional activities and land uses provide valuable information, often hard to come by, for better understanding present structures and functions of forest ecosystems. Forest policies and management actions of the past help to improve our current knowledge and future planning. Raum (2020) in her perspective paper describes how current forest landscapes in the UK are strongly influenced by the legacies of decisions, policies and management activities over the last 100 years.

4 Land-use change geographic datasets to understand ongoing disturbance regime alterations in a global change context Shifting forest disturbance regimes are commonly associated with climate change, but an important role is also played by the legacy of past land-use on rural-forest landscapes. Mantero et al. (2020) present a global scale review that highlights the fundamental influence of landuse change due to marginalization and abandonment of rural/mountain areas in different parts of the world. Their findings provide strong evidence of land-use legacy effects on disturbance regimes, mostly in the Mediterranean region. 
Taken together, these case studies provide a comprehensive survey of the state-of-the-art in using reconstructions of historical land-use to refine our understanding and predictive capacity with regard to future landscape change. In most forested regions of the world, land-use legacies serve to constrain and modulate future landscape trajectory and response to environmental stressors. Understanding their impacts requires a multidisciplinary approach that draws heavily on the historical sciences, in addition to the classical tools and paradigms already familiar to landscape ecologists (Gimmi and Bugmann 2013).

\section{References}

Bürgi M, Östlund L, Mladenoff DJ (2017) Legacy effects of human land use: ecosystems as time-lagged systems. Ecosystems 20(1):94-103

Farina A (2000) The cultural landscape as a model for the integration of ecology and economics. Bioscience 50(4):313-320

Foster D, Swanson F, Aber J, Burke I, Brokaw N, Tilman D, Knapp A (2003) The importance of land-use legacies to ecology and conservation. Bioscience 53:77-88

Garbarino M, Lingua E, Subira MM, Motta R (2011) The larch wood pasture: structure and dynamics of a cultural landscape. Eur J For Res 130:491-502

Garbarino M, Lingua E, Marzano R, Urbinati C, Bhuju D, Carrer M (2014) Human interactions with forest landscape in the Khumbu valley. Nepal Anthropocene 6:39-47
Garbarino M, Morresi D, Urbinati C, Malandra F, Motta R, Sibona EM, Vitali A, Weisberg PJ (2020) Contrasting land use legacy effects on forest landscape dynamics in the Italian Alps and the Apennines. Landsc Ecol. https://doi. org/10.1007/s10980-020-01013-9

Gimmi U, Bugmann H (2013) Preface: integrating historical ecology and ecological modeling. Landsc Ecol 28:785-787

Klimaszewski-Patterson A, Mensing S (2020) Paleoecological and paleolandscape modeling support for pre-Columbian burning by Native Americans in the Golden Trout Wilderness Area. Landsc Ecol, California, USA. https:// doi.org/10.1007/s10980-020-01081-x

Mantero G, Morresi D, Marzano R, Motta R, Mladenoff DJ, Garbarino M (2020) The influence of land abandonment on forest disturbance regimes: a global review. Landsc Ecol (in review)

Mensing S, Schoolman EM, Palli J, Piovesan G (2020) A consilience-driven approach to land use history in relation to reconstructing forest land use legacies. Landsc Ecol. https://doi.org/10.1007/s10980-020-01079-5

Raum S (2020) Land-use legacies of twentieth-century forestry in the UK - a perspective. Landsc Ecol. https://doi.org/10. 1007/s10980-020-01126-1

Ridding LE, Newton AC, Redhead JW, Watson SC, Rowland CS, Bullock JM (2020) Modelling historical landscape changes. Landsc Ecol. https://doi.org/10.1007/s10980020-01059-9

Vos W, Meekes H (1999) Trends in European cultural landscape development: perspectives for a sustainable future. Landsc Urban Plan 46(1-3):3-14

Publisher's Note Springer Nature remains neutral with regard to jurisdictional claims in published maps and institutional affiliations. 